\title{
Linkage analysis of the human insulin receptor gene and maturity onset diabetes of the young
}

\author{
S.C.Elbein ${ }^{1}$, I. Borecki ${ }^{2}$, L.Corsetti ${ }^{2}$, S.S. Fajans ${ }^{3}$, A. T. Hansen ${ }^{4}$, J. Nerup ${ }^{4}$, M. Province ${ }^{2}$ and M. A.Permutt ${ }^{2}$ \\ ${ }^{1}$ VAMC and University of Utah School of Medicine, Salt Lake City, Utah, ${ }^{2}$ Washington University School of Medicine, St. Louis, Missouri, \\ ${ }^{3}$ University of Michigan Medical Center, Ann Arbor, Michigan, USA, ${ }^{4}$ Steno Memorial Hospital, Gentofte, Denmark
}

Summary. The cloning of the insulin receptor cDNA has permitted the definition of restriction fragment length polymorphisms at that locus. These polymorphisms were used to study the role of the insulin receptor in four pedigrees with maturity onset diabetes of the young through linkage analyses. When each pedigree was individually analysed, no linkage was demonstrated in the two larger pedigrees, implying that an insulin receptor defect was not responsible for the predisposition to diabetes in these pedigrees. One of these pedigrees was known to be hypoinsulinaemic, while insulin levels were unavailable in the second pedigree. In the two smaller pedigrees, however, a single haplotype cosegregated with diabetes. One of these pedigrees is known to be hyperinsulinaemic. The small size of the pedigrees which demon- strated cosegregation precluded statistical proof of linkage. Nonetheless, the presence of an uncommon insertional polymorphism which cosegregated with diabetes in both pedigrees was improbable and suggested that this insertion could be responsible for diabetes in these families. This study thus may be additional evidence for heterogeneity in maturity onset diabetes of the young. For the two larger pedigrees, the insulin gene and HLA region have already been eliminated as genetic markers. This study provides data which eliminate a third candidate gene in these two pedigrees.

Key words: Maturity onset diabetes of the young (MODY), insulin receptor, linkage analysis.
The inherited nature of Type 2 (non-insulin-dependent) diabetes has been well documented [1]. Nonetheless, the mode of inheritance remains uncertain, perhaps because of genetic heterogeneity within the Type 2 diabetic phenotype. One subgroup which may represent a genetically distinct entity is maturity onset diabetes of the young, or MODY, which is distinguished by the onset of mild hyperglycaemia without ketosis in children, adolescents and young adults. In distinction to more common Type 2 diabetes, the pattern of inheritance of MODY is highly suggestive of autosomal dominant transmission [2], which in combination with the early penetrance makes this disease an ideal model for genetic studies of diabetes. The exact prevalence of MODY and its relationship to Type 2 diabetes is uncertain, and this disease may represent a sizable and unrecognised subset of non-insulin-dependent diabetes.

Studies of the diabetic members of MODY pedigrees have shown both familial hyperinsulinaemic and hypoinsulinaemic patterns [3], although most MODY individuals appear to be relatively hypoinsulinaemic $[4,5]$. Because both insulin secretion and insulin action are subject to secondary fluctuations [6-8], insulin levels in individuals expressing the diabetic phenotype may not reflect the predisposing genotype. Available data could therefore be interpreted as consistent with primary defects of insulin production or insulin action; either may result in the MODY phenotype. The data from insulin secretory responses in diabetic individuals suggest that MODY is heterogeneous [3,9]. Nonetheless, the uniformly autosomal dominant mode of inheritance in MODY makes examination of this disease under the hypothesis of a single dominant gene appropriate pending genetic evidence for heterogeneity.

The search for a genetic marker for MODY has thus far been unsuccessful. No association has been found between specific HLA antigens (chromosome 6) and MODY [10-13]. Studies of linkage of the region of tandem repeats upstream from the insulin gene and MODY have likewise been negative in several pedigrees [14-17]. Recently another candidate for the genetic predisposition to diabetes, the insulin receptor gene, was cloned $[18,19]$, and several DNA sequence polymorphisms, or restriction fragment length polymorphisms (RFLP) have been defined [20] which make 
this locus highly informative for linkage analysis. We have thus tested the hypothesis that a defect of the insulin receptor was responsible for the diabetes of two large MODY pedigrees and two smaller ones. Since the two smaller pedigrees had not previously been tested for insulin gene involvement, we likewise tested linkage to the insulin gene in these pedigrees, using additional markers which make this locus more informative than previously possible [21].

\section{Subjects and methods}

\section{Pedigrees}

Four pedigrees were included in the analysis. The J pedigree consists of 56 members as reported elsewhere [15,22], of which 42 DNA samples were available for the present study. The large R-W pedigree has likewise been extensively studied $[3,5,16,23]$. For this pedigree the current study included only members of branch II-5, since analysis of other branches was not informative for linkage and contributed little to the analysis. The two smaller pedigrees (Va and $\mathrm{Ho}$ ) have also been reported elsewhere [3], but since complete clinical data has not been reported previously, this data is included in Table 1. The age of diagnosis in these pedigrees varies from under 25 years of age to 86 years of age. Since MODY may be asymptomatic for decades, the age of diagnosis will often be delayed in older generations. The establishment of the diagnosis in younger individuals of- ten requires routine screening tests. Since the Va and Ho pedigrees had not been previously evaluated at the insulin locus, both insulin and insulin receptor studies were included. For all pedigrees, DNA was prepared from 10 to $20 \mathrm{ml}$ of anticoagulated peripheral blood by harvesting leukocytes and extracting DNA as previously described [24].

\section{Restriction-fragment length polymorphisms}

For each DNA sample, $5 \mu \mathrm{g}$ was digested overnight with a five-fold excess of the appropriate restriction enzyme under conditions specified by the manufacturer (International Biotechnologies, Inc., New Haven, Conn; Bethesda Research Laboratories, Gaithersburg, Md; or New England Biolabs, Beverly, Mass, USA). Restriction digests were separated by electrophoresis on $0.8 \%$ to $1.2 \%$ agarose gels and blotted by Southern transfer to Zetabind (AMF Cuno, Meriden, Conn, USA), as previously described [20, 21]. Filters were hybridized with DNA probes appropriate to detect the RFLP described below, labelled with ${ }^{32} \mathrm{P}$ dCTP (ICN, Irvine, Calif; New England Nuclear, Boston, Mass, USA) by nick translation [25].

For studies of the insulin gene (HINS), the region of tandem repeats in the $5^{\prime}$ flanking region was analyzed with the restriction enzyme Pvu II and the specific probe for this region, pPvuII 1.3 [21]. As previously described, this enzyme provides the maximum available information for this locus [21]. Other RFLP at Taq I and Rsa I sites (11 and 13 kilobase pairs upstream from the insulin gene respectively) were detected by probe pHINS 6.0 [21], and another region of tandem repeats at the nearby $\mathrm{H}$-Ras oncogene locus (HRAS) was detected with a third probe, pTBB2 $[21,26]$. These four RFLP constitute a single genetic locus for analysis, although a $3 \%$ recombination frequency between the HINS and HRAS loci is reported [27].

Table 1. Clinical information on pedigrees $\mathrm{Ho}$ and $\mathrm{Va}$

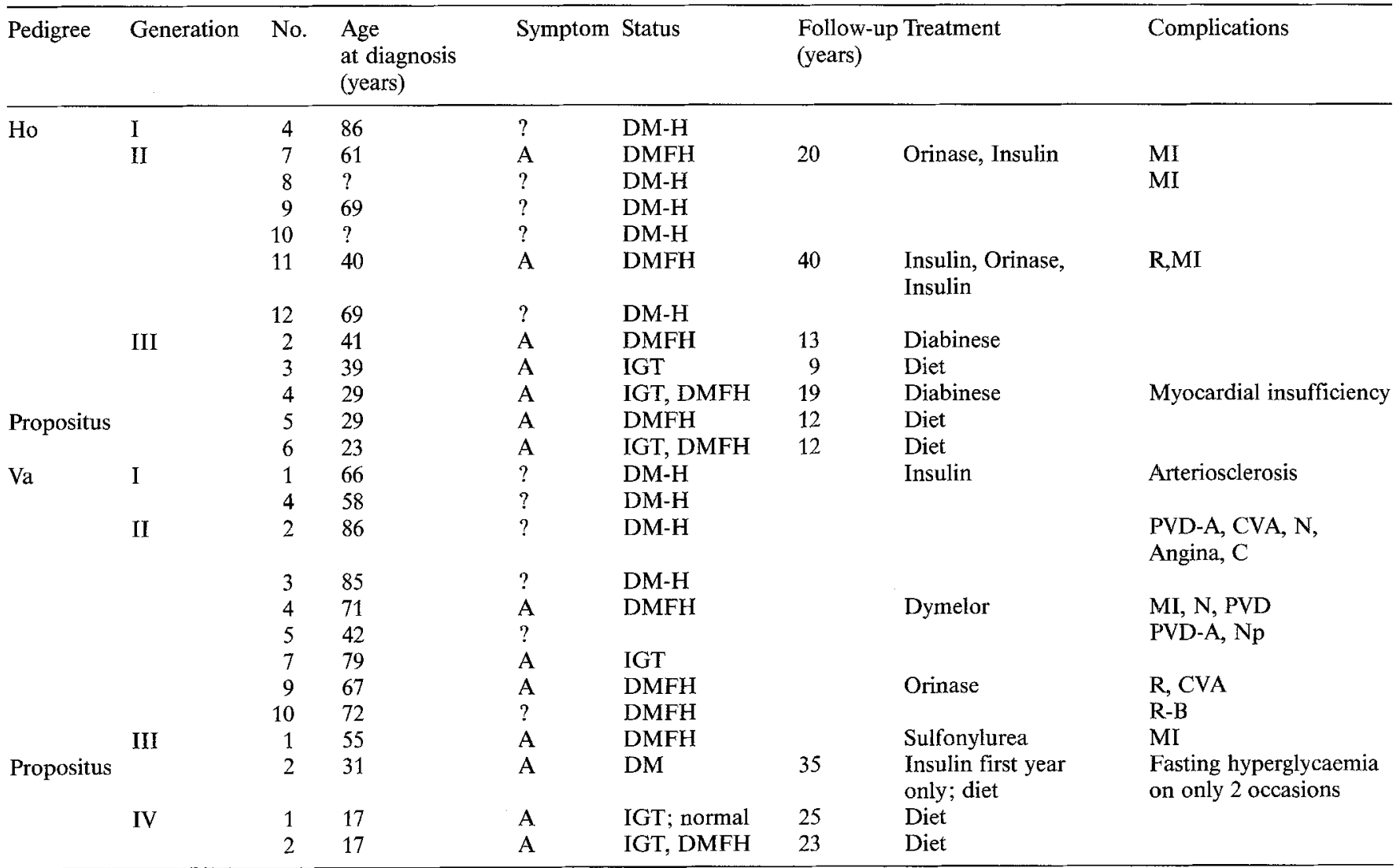

Ho III 2-6 had routine tests for insurance purposes when hyperglycaemia was discovered. A=asymptomatic; DM-H = history of diabetes mellitus; $\mathrm{DMFH}=$ diabetes with fasting hyperglycaemia; $\mathrm{IGT}=$ impaired glucose tolerance; $\mathrm{MI}=$ myocardial infarction; $\mathrm{R}=$ retinopathy; $\mathrm{R}-\mathrm{B}=$ retinopathy, blindness; $\mathrm{PVD}-\mathrm{A}=$ peripheral vascular disease, amputation; $\mathrm{CVA}=$ cerebrovascular accident; $\mathrm{N}=$ neuropathy; $\mathrm{Np}=\mathrm{ne}-$ phropathy; $\mathrm{C}=$ cataract 
Ho

I

III
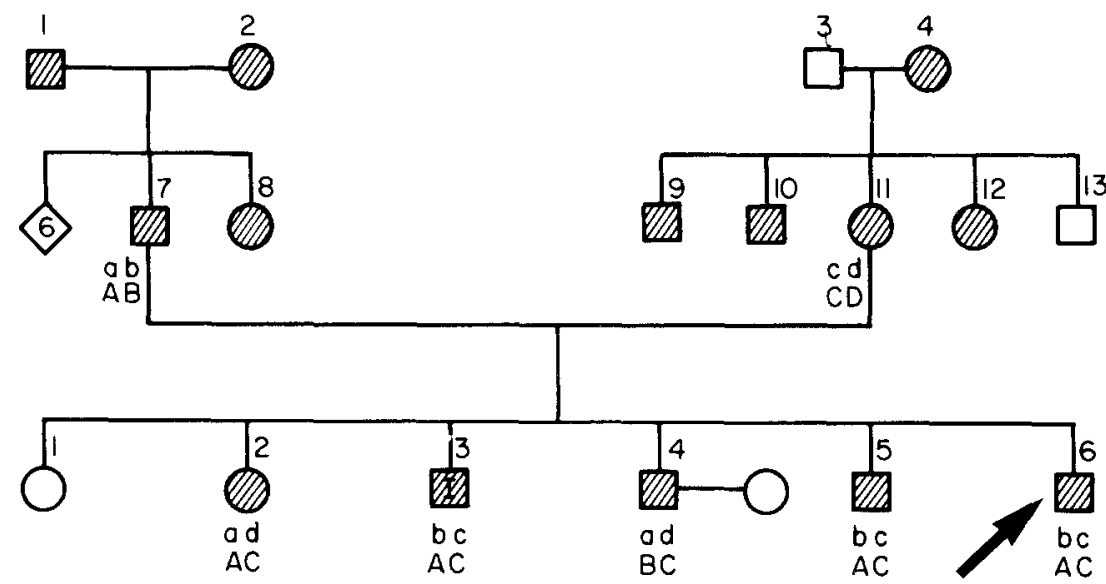

HINS

\begin{tabular}{c|cccc}
\multicolumn{1}{c}{} & $a$ & $b$ & $c$ & $d$ \\
\cline { 2 - 5 } Rsa & + & + & + & - \\
Taq & + & + & + & + \\
PvuII & 0.90 & 0.96 & 0.96 & 2.3 \\
HRAS & 2.6 & 3.6 & 3.0 & 2.6
\end{tabular}

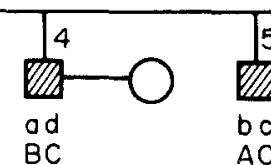

$A C$

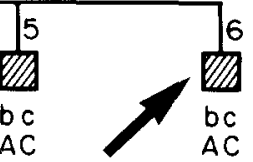

$\mathrm{AC}$

$\mathrm{Va}$

I

II

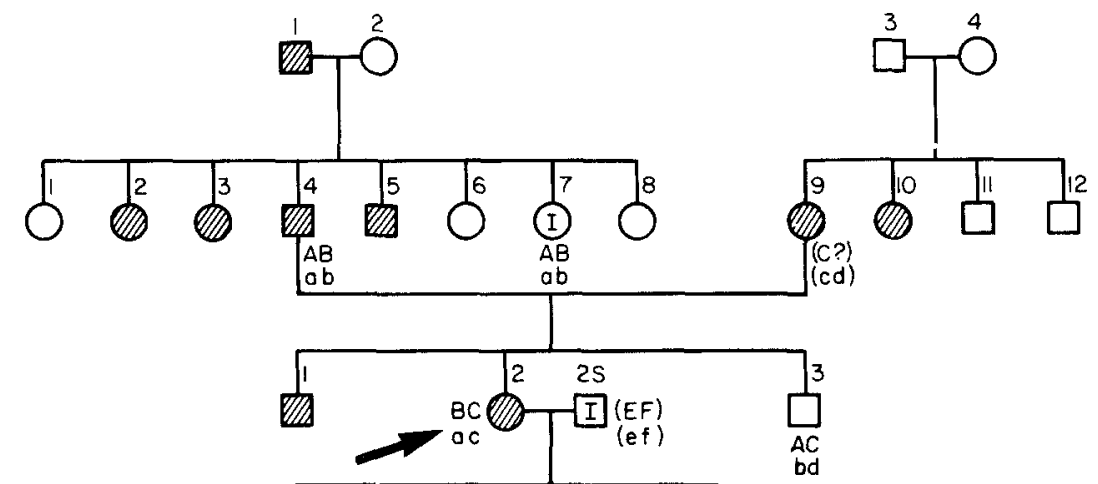

III

IV

Z

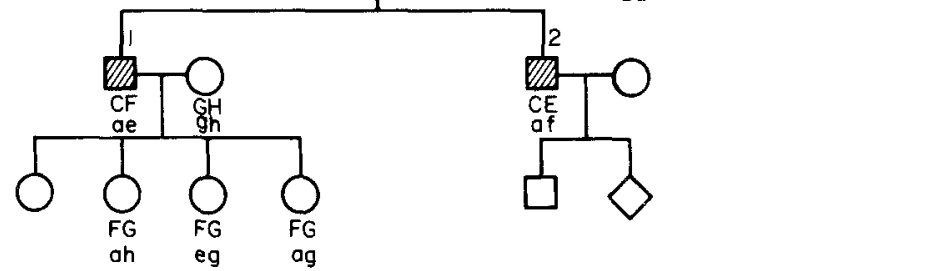

Fig. 1. Pedigree and linkage analysis of the Ho pedigree. Male members are denoted as squares, females as circles, and affected individuals by shaded symbols. The proband is designated with an arrow. Although shaded, the individuals I-1 and I-2 (deceased) are not certain to have been diabetic. Insulin gene haplotypes are shown below the symbols in small letters, as defined in the Table below the Figure under HINS. For all RFLP, absence of a site is denoted ' - ', presence of a restriction site " + '. For the insulin gene, $5^{\prime} \mathrm{FP}$ denotes the region of tandem repeats, and alleles are referred to by size in $\mathrm{kb}$. The HRAS locus (the tandem repeat region downstream from the c-Ha-Ras oncogene) is similarly denoted. Insulin receptor haplotypes are designated by capital letters, and are also defined in a table below the Figure under HIR. No allele is shared for the insulin gene, but allele $\mathrm{C}$ is shared by all related diabetic patients for the insulin receptor gene
Fig. 2. Analysis of the Va pedigree. Members and affected individuals are denoted as in Figure 1. Individual IV-1 has impaired glucose tolerance. Insulin gene analysis is denoted by small letters which define the haplotypes shown in the Table below (HINS), and as discussed in Figure 1. Inferred haplotypes are shown in parentheses. Insulin receptor analysis is similarly shown in capital letters and in the Table HIR. For the insulin gene analysis, allele $\mathrm{A}$ is shared by the diabetic patients who are descendants of individual II-4, while for the insulin receptor analysis, allele $\mathrm{C}$ is shared by the descendants of individual II-9. Neither cosegregation achieves statistical significance. For the HIR analysis, allele D was assigned to individual II-9, but since this allele was not inherited by subsequent generations, no haplotype data could be inferred and this column was left blank in the HIR Table. Individual III-1 died of accidental causes at age 10 , and was unavailable for analysis 


\section{$R-W$}

II

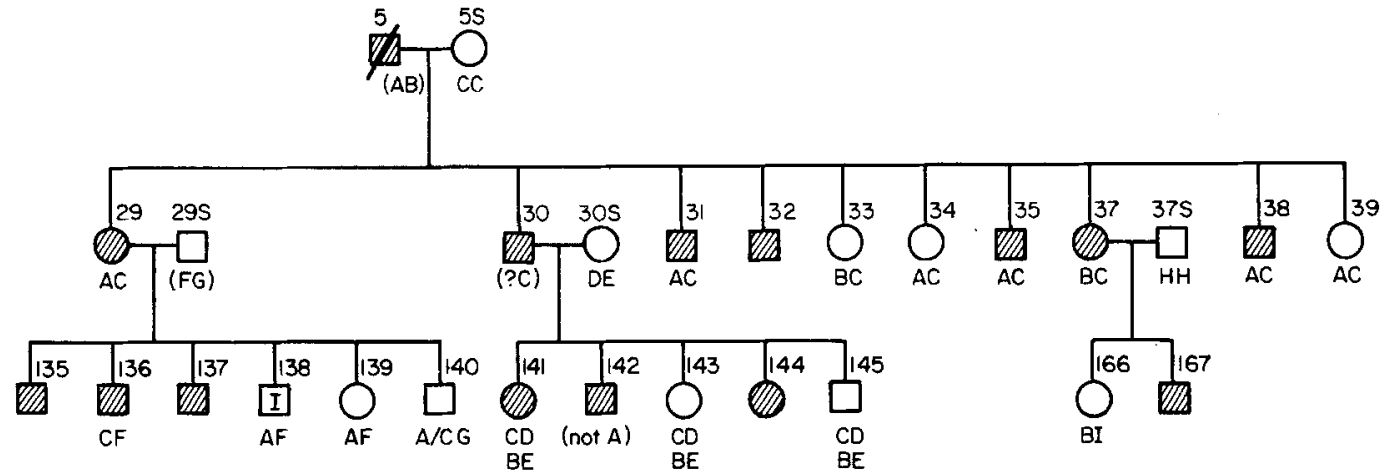

III

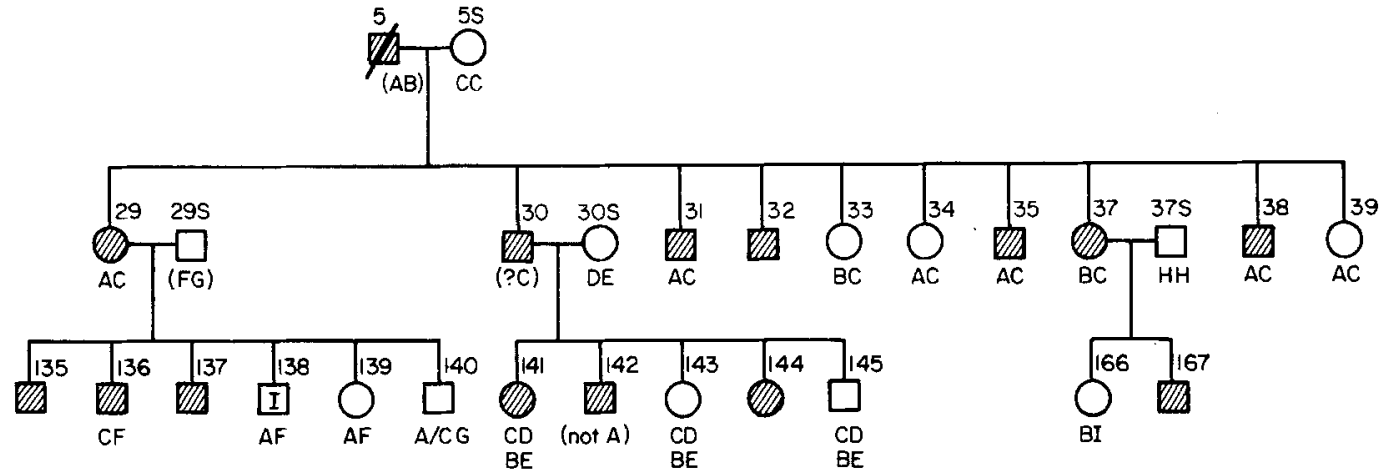

IV

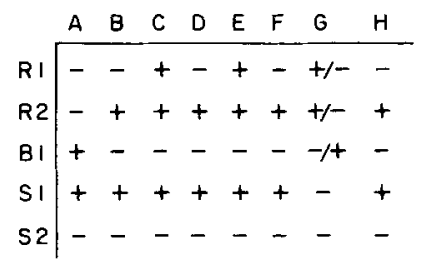

Fig.3. Analysis of the R-W pedigree. One branch of the R-W pedigree is shown, beginning with the second generation. Symbols are as previously described. Only analysis of the insulin receptor for the descendants of individual II- 5 is shown. Where ambiguities were present, all possibilities are shown. Thus, individuals IV-141, 143, and 145 have either of the two genotypes shown. Neither allele inherited from individual II- 5 is shared by the affected individuals in the pedigree

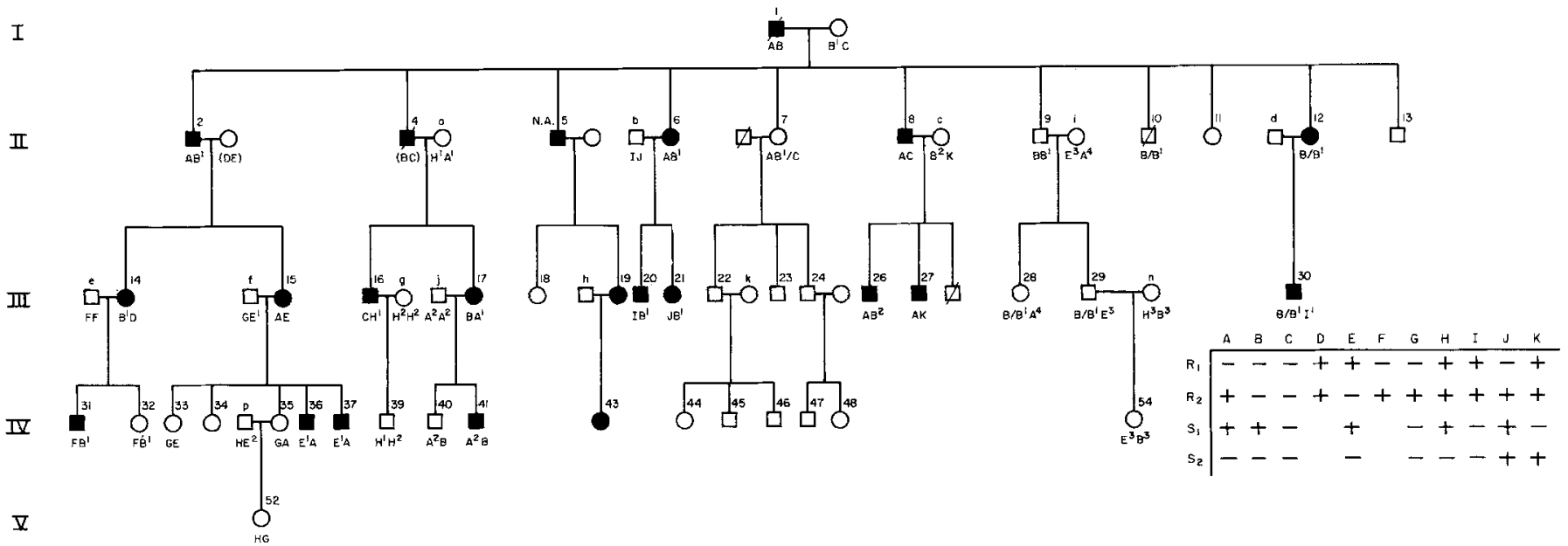

Fig.4. Insulin receptor analysis of pedigree $J$. The entire pedigree is shown, with symbols as previously described. Identical hyplotypes were given the same letter. Where such identical haplotypes could be distinguished by the pattern of inheritance, they were so designated with different superscripts. Thus, alleles such as B and B1 have identical marker patterns (see the Table), but are clearly represent different alleles by pattern of inheritance. No single allele is shared by the diabetic patients in generation II, which the analysis of generation II confirms. In the few cases where marker phase could not be unambiguously established, both possibilities are shown

Studies of the insulin receptor (INSR) utilised two probes. Polymorphisms at two Sac I sites (S1 and S2) were detected with probe 12.1P1.6, as was an RFLP at a Bgl II site (B1). Two additional polymorphisms at Rsa I sites were detected with probe $12.1 \mathrm{~B} 1.3$, and are called R1 and R2, as previously described [20]. Since the RFLP B1 is in a high degree of linkage equilibrium with polymorphism $\mathrm{R} 2$, the Bgl II analysis is redundant for most purposes [20] and was not included in all pedigrees. All polymorphisms represent the presence or absence of a restriction site and are denoted + or -, except for \$1, which although similarly designated actually represents a $500 \mathrm{bp}$ insertion in the '-' allele (unpublished observations).

\section{Linkage analysis}

For both studies, each family was initially considered individually for linkage. For both the insulin gene and the insulin receptor gene, the hypothesis of gene involvement was tested by assuming a recombination fraction of $0(\theta=0)$, and by examining only known affected individuals as previously described $[3,5,15,16,22]$. Thus, failure of all affected individuals to share a single allele would rule out linkage and thus eliminate the gene from consideration as causing diabetes in that family. Since the larger pedigrees ( $\mathrm{J}$ and R-W) had previously been studied at the insulin locus, this study was not repeated. For all 
Table 2. Lod scores (logarithm of the odds for linkage versus nonlinkage) for linkage between insulin receptor gene polymorphisms and MODY

\begin{tabular}{lc}
\hline Recombination fraction $(\Theta)$ & Lod score \\
\hline 0.05 & -7.65 \\
0.10 & -3.95 \\
0.15 & -2.06 \\
0.20 & -0.94 \\
0.25 & -0.26 \\
0.30 & 0.13 \\
0.35 & 0.31 \\
0.40 & 0.33 \\
0.45 & 0.22 \\
\hline
\end{tabular}

four pedigrees, the RFLP permitted the identification of sufficient haplotypes to distinguish the parental alleles without ambiguity when phase between markers was established by the patterns of Mendelian inheritance. Each haplotype was then assigned a letter, as shown in Figures 1-4. For simplicity, identical insulin receptor haplotypes which were distinguishable by patterns of inheritance were given the same letter but were distinguished by superscript in the J pedigree (Fig. 4). For other pedigrees separate letters were used where alleles were distinguishable by haplotype or by pattern of inheritance. Unambiguously inferred haplotypes for unavailable individuals were included in the analysis.

The hypothesis of linkage was formally tested by calculation of the lod score, or the logarithm of the odds for linkage versus nonlinkage, using the program package LINKAGE [28] at recombination fractions $(\theta)$ from 0 (no recombination, or tight linkage) to 0.5 (no linkage), as shown in Table 2. Calculation of lod scores assumed that the MODY gene was autosomal dominant and fully penetrant, and assumed a low spontaneous mutation rate of $10^{-6}$. The five RFLP around the insulin receptor locus were treated as a single locus with 7 alleles with equal allelic frequencies, since for lod calculations actual gene frequencies have been demonstrated to be irrelevant $[29,30]$. In contrast to the initial analysis, which assumed a recombination fraction of 0 and no spontaneous mutation, and which treated each family individually, lod calculation pooled the data from the four pedigrees, and thus assumed genetic uniformity.

\section{Results}

\section{Insulin gene studies}

For both the R-W and $\mathrm{J}$ pedigrees previous analysis had shown lack of linkage between MODY and HINS. Analysis of the Ho pedigree showed similar lack of linkage (Fig.1), while analysis of the Va pedigree showed sharing of allele 'a' among four diabetic patients (Fig. 2). This sharing does not approach statistical significance, however.

\section{Insulin receptor gene studies}

Initial analysis treated each pedigree individually and tested only the hypothesis that the MODY gene was a defect of the insulin receptor gene. Thus no recombination between the receptor polymorphisms and MODY would be anticipated, and failure of a given insulin receptor gene haplotype to cosegregate with MODY in a pedigree would disprove the linkage hypothesis.
Analysis of the insulin receptor gene in the R-W pedigree identified three of four possible haplotypes from generation II. Since the alleles of individual II- $5 \mathrm{~s}$ were indistinguishable, all generation III individuals shared haplotype $C$ (Fig. 3). However, two haplotypes (A and B) were inferred for individual II-5, and since autosomal dominant inheritance would require transmission of the defect from this individual, linkage would require sharing of haplotype A or B among all affected family members. Despite difficulties in establishing marker phase in generation IV with resulting ambiguous haplotype assignments, the linkage hypothesis is clearly disproved.

For pedigree $\mathrm{J}$, analysis permitted four first generation alleles to be distinguished (Fig.4). Autosomal dominant transmission would require a defect to reside in allele A or B (inferred without ambiguity to originate from individual I-1). Neither of these alleles and no other single allele is shared by the affected individuals.

Individual analysis of the Ho and Va pedigrees was again limited by the small size of these pedigrees, and proof of linkage was thus not possible. In each case a single allele is shared by the affected individuals, but analysis for both pedigrees is further complicated by the occurrence of diabetes on both maternal and paternal relatives. For family Ho, allele $\mathrm{C}$ is shared by the five affected offspring, but when the proband is removed from analysis, the odds in favor of linkage do not reach significance. For pedigree Va (Fig.2), allele $\mathrm{C}$ is again shared by four individuals, but significance is not approached. Interestingly, in both cases the haplotype shared includes the "- " allele of RFLP $\mathrm{S} 1$, which represents the $500 \mathrm{bp}$ insertion (unpublished observations). Since this RFLP has a frequency in the Caucasian population of only 0.12 [20], the probability that both pedigrees would demonstrate cosegregation of this polymorphism with diabetes by chance alone becomes quite small $(p<0.01)$.

While individual analysis of each pedigree is adequate to draw conclusions regarding the role of the insulin receptor or insulin genes in these pedigrees, linkage at a finite recombination frequency could still be compatible with lack of sharing of a single allele among every affected individual. To detect such weaker linkage, which might implicate as yet undefined genes in the region of the insulin receptor gene, we performed a formal linkage analysis between the insulin receptor locus and MODY with calculation of the statistic "lod", or logarithm of the odds ratio for linkage, using the computer program "LINKAGE" [28]. At each recombination fraction $(O)$ between 0 (complete linkage) and 0.5 (no linkage) the likelihood of obtaining the results observed is calculated and compared to the likelihood of observing those results by chance alone $(\Theta=0.5)$, as expressed by a likelihood ratio, or "odds" (Table 2). The logarithm of the odds, lod, is expected to be near 0 if linkage at a certain recombina- 
tion fraction and nonlinkage are equally likely, positive if linkage is more likely, and negative if linkage is unlikely. By convention, a lod score of 3 (1000:1 odds for linkage) is considered proof of linkage, while a score of -2 (100:1 odds against linkage) is taken as evidence against linkage. By this calculation for the four pedigrees considered together, tight linkage is clearly rejected. Indeed, for all recombination fractions up to 0.15 ( 15 centimorgans), the lod score is below -2 . At recombination fractions higher than 0.15 , the lod score is indeterminate, and linkage at these distances cannot be rejected with certainty.

\section{Discussion}

Insulin gene analysis in the current study confirmed earlier studies, and further suggests that insulin gene defects cannot be implicated in the predisposition to MODY. The insulin receptor has not been previously evaluated. Although no consistent evidence exists for insulin resistance in MODY, hyperinsulinaemic pedigrees have been noted, and the Ho family of the present study represents such a pedigree [9]. Insulin receptor defects could thus be important in the MODY phenotype. Such defects are known to occur in the rare autosomal recessive disorders of extreme insulin resistance, such as leprechaunism, type A insulin resistance associated with acanthosis nigricans, and lipoatrophic diabetes [31, 32]. The allelic frequency of such defects could be high, and the effect of insulin receptor mutations in the predisposition to Type 2 diabetes or MODY could be significant. Studies of insulin binding and insulin stimulated tyrosine kinase activity are subject to secondary fluctuations and the limitations of measurement which may make detection of heterozygous defects impossible. Furthermore, such studies would not detect defects in regions of the large receptor molecule which are not easily subject to measurement. Linkage studies, especially in diseases with simple patterns of inheritance, provide definitive data on the involvement of this gene without such limitations.

The results in the two large pedigrees ( $\mathrm{J}$ and R-W) provide convincing evidence that insulin receptor defects are not responsible for the diabetes in these families. While insulin levels and insulin sensitivity data are not available for the $J$ pedigree, previous studies of the $\mathrm{R}-\mathrm{W}$ pedigree suggested hypoinsulinaemia and normal insulin sensitivity, and the evidence against insulin receptor defects is therefore not surprising. Thus, for these pedigrees, no genetic marker is currently available, but three candidate loci (HLA, HINS, and INSR) have been eliminated. The recent successes in the application of random DNA markers to mapping inherited diseases with a uniform mode of inheritance [33, 34] suggest that a general linkage approach may be valuable in these pedigrees. The data presented here and in earlier studies [10-17], although negative, will be valuable in focusing that approach.
In the smaller Va and hyperinsulinaemic Ho pedigrees, cosegregation of a single insulin receptor haplotype was noted. The small size of these pedigrees precludes proof of linkage without the pooling of these data with that from the larger pedigrees. Such pooling would assume that MODY is a uniform disease. Under that model, the cosegregation of a receptor allele in these pedigrees would be considered a chance event. The presence of an unusual insertion in the implicated haplotypes of both pedigrees is highly improbable, however, and suggests a need for further evaluation. These pedigrees are different from the larger ones in that diabetes enters the family from individuals on both paternal and maternal sides, and in the case of the Ho family, insulin levels were high [9]. Thus, the MODY phenotype in these families may not represent a single genetic locus. In this setting, an insertional polymorphism of the insulin receptor may be necessary but not sufficient for the expression of diabetes. The presence of this insertion in the J pedigree, where it is not contributed by the first generation diabetic individuals and does not cosegregate with diabetes, is consistent with this hypothesis.

The molecular nature of the $\mathrm{S} 1$ polymorphism is unknown. The insertion has been mapped to the region of the insulin receptor cDNA which codes for the $\beta$ chain, between base pairs 2744 and 2963 . The exact location with regard to coding or non-coding sequences is currently unknown. While the insertion is unusual in Caucasian individuals, it is present in $30 \%$ of American Blacks [20]. Studies in progress should help clarify the significance of the current findings.

These pedigrees are among the first to be evaluated for insulin receptor involvement in diabetes, and the current study demonstrates the feasibility of linkage studies with the insulin receptor gene using the currently defined polymorphisms. The lack of linkage in two large MODY pedigrees suggests that further studies of this locus in Caucasian pedigrees with clearly autosomal dominant MODY are likely to be negative. Similar studies will help define the role of the insulin receptor in other Type 2 diabetic pedigrees. Additionally, the examination of other MODY pedigrees with more complicated patterns of inheritance, and in particular with hyperinsulinaemia, may provide further insight into the role of receptor defects in such families.

\footnotetext{
Acknowledgments. We wish to thank Dr. A. Ullrich for providing the insulin receptor cDNA from which the probes for this study were constructed, and Dr. P. Rotwein for providing DNA from which the insulin gene probes were derived. This work was supported by grants AM-31866 and AM-16746 from the National Institutes of Health (M.A.P.), NIH-5 M01 RR-42 General Clinical Research Centers Grant (S.S.F.) and Michigan Diabetes Research and Training Center Grant 5-P60-AM20572. S.C.E. was the recipient of National Research Service Award AM-07120 from the National Institute of Arthritis, Diabetes, and Digestive and Kidney Diseases, and is supported by the research service of the V.A.M.C.
} 


\section{References}

1. Rotter JI, Rimoin DL (1981) The genetics of the glucose intolerance disorders. Am J Med 70: 116-126

2. Tattersall RB, Fajans SS (1975) A difference between the inheritance of classic juvenile-onset and maturity onset type of diabetes of young people. Diabetes 24: 44-53

3. Fajans SS (1982) Heterogeneity between various families with non-insulin dependent diabetes of the MODY type. In: Köbberling $\mathrm{J}$, Tattersall $\mathrm{R}$ (eds) The genetics of diabetes mellitus. Academic Press, London New York, pp 251-260

4. Barbosa J, Ramsay R, Goetz FC (1978) Plasma glucose, insulin, glucagon, and growth hormone in kindreds with maturity-onset type of hyperglycaemia in young people. Ann Int Med 88: 595-601

5. Fajans SS (1985) Heterogeneity within Type II and MODY diabetes. In: Vranic M (ed) Comparison of Type I and Type II Diabetes. Advances in experimental medicine and biology. Plenum, New York, pp 65-87

6. Turner RC, McCarthy ST, Holman RR, Harris E (1976) Beta-cell function improved by supplementing basal insulin secretion in mild diabetes. Br Med J 1: 1252-1254

7. Grunberger G, Taylor SI, Dons RF, Gordon P (1983) Insulin receptors in normal and disease states. J Clin Endocrinol Metab 12: $191-219$

8. Garvey WT, Olefsky JM, Griffin J, Hamman RF, Kolterman OG (1985) The effect of insulin treatment on insulin secretion and insulin action in type II diabetes mellitus. Diabetes 34: 222-232

9. Fajans SS (1986) Heterogeneity of insulin secretion in Type II diabetes. In: Defronzo RA (ed) Diabetes/metabolism reviews, Vol 2, Nos 3 and 4. John Wiley, New York, pp 347-361

10. Platz P, Jakobsen BK, Svejgaard A, Thomsen BS, Jensen KB, Henningsen K, Lamm LU (1982) No evidence for linkage between HLA and maturity onset type of diabetes in young people. Diabetologia 23: 16-18

11. Barbosa J (1983) No linkage between HLA and maturity onset hyperglycaemia in the young. Diabetologia 24: 137-140

12. Nelson PG, Pyke DA (1976) Genetic diabetes not linked to the HLA locus. Br Med J 1: 196-197

13. Tattersall RB (1982) The present status of maturity onset type of diabetes of young people (MODY). In: Köbberling J, Tattersall R (eds) The genetics of diabetes mellitus. Academic Press, London New York, pp 260-270

14. Bell JI, Wainscoat JS, Old JM, Chlouverakis C, Keen H, Turner RC, Weatherall DJ (1983) Maturity onset diabetes of the young is not linked to the insulin gene. Br Med J 286: 590-592

15. Owerbach D, Thomsen B, Johansen $K$, Lamm LU, Nerup J (1983) DNA insertion sequences near the insulin gene are not associated with maturity-onset diabetes of young people. Diabetologia $25: 18-20$

16. Andreone T, Fajans SS, Rotwein P, Skolnick M, Permutt MA (1985) Insulin gene analysis in a family with maturity onset diabetes of the young. Diabetes 34: 108-114

17. Johnston C, Owerbach D, Leslie RDG, Pyke DA, Nerup J (1984) Mason-type diabetes and DNA insertion polymorphism. Lancet $1: 280$

18. Ullrich A, Bell JR, Chen EY, Herrera R, Petruzzelli LM, Dull TJ, Gray A, Coussens L, Liao YC, Tsubokawa M, Mason A, Seeburg PH, Grunfeld C, Rosen OM, Ramachandran J (1985) Human insulin receptor and its relationship to the tyrosine kinase family of oncogenes. Nature 313: 756-761
19. Ebina Y, Ellis L, Jarnagin K, Edery M, Laszlo G, Clauser E, Ou J, Masiarz F, Kan YW, Goldfine ID, Roth RA, Rutter WJ (1985) The human insulin receptor cDNA: the structural basis for hormone-activated transmembrane signalling. Cell 40: 747-758

20. Elbein SC, Corsetti L, Ullrich A, Permutt MA (1986) Multiple restriction fragment length polymorphisms at the insulin receptor locus: a highly informative marker for linkage analysis. Proc Natl Acad Sci USA 83: 5223-5227

21. Elbein SC, Corsetti L, Permutt MA (1985) New polymorphisms at the insulin locus increase its usefulness as a genetic marker. Diabetes 34: 1139-1144

22. Johansen K, Gregersen G (1977) A family with dominantly inherited mild juvenile diabetes. Acta Med Scand 201: 567-570

23. Fajans SS, Cloutier MC, Crowther RL (1978) Clinical and etiologic heterogeneity of idiopathic diabetes mellitus. Diabetes 27: $1112-1114$

24. Bell KI, Karam JH, Rutter WJ (1981) Polymorphic DNA region adjacent to the $5^{\prime}$-end of the human insulin gene. Proc Natl Acad Sci USA 78: $5759-5763$

25. Rigby PWJ, Dieckmann M, Rhodes C, Berg P (1977) Labelling deoxyribonucleic acid to high specific activity in vitro by nick translation with DNA polymerase 1. J Mol Biol 113: 237-251

26. Capon DJ, Chen EY, Levinson AD, Seeburg PH, Goeddel DV (1983) Complete nucleotide sequences of the T24 human bladder carcinoma oncogene and its normal homologue. Nature 302: 33-37

27. White R, Leppert M, Bishop DT, Barker D, Berkowitz J, Brown C, Callahan P, Holm T, Jerominski L (1985) Construction of linkage maps with DNA markers for human chromosomes. Nature 313: 101-105

28. Lathrop GM, Lalouel JM (1984) Easy calculation of lod scores and genetic risks on small computers. Am J Hum Genet 36: $460-465$

29. Ott J (1985) Analysis of human genetic linkage, John Hopkins Univ Press, Baltimore, pp 162-163

30. Ott J (1978) A simple scheme for the analysis of HLA linkages in pedigrees. Ann Hum Genet 42: 225-57

31. Taylor S (1985) Receptor defects in patients with extreme insulin resistance. Diabetes/Metabol Rev 1: 171-202

32. Hedo JA, Moncada VY, Taylor SI (1985) Insulin receptor biosynthesis in cultured lymphocytes from insulin resistant patients. $\mathbf{J}$ Clin Invest 76: 2355-2361

33. White R, Woodward S, Leppert M, O'Connell P, Hoff M, Herbst J, Lalouel JM, Dean M, Vande Woude G (1985) A closely linked genetic marker for cystic fibrosis. Nature 318: 382-384

34. Gusella JF, Wexler NS, Conneally PM, Naylor SL, Anderson MA, Tanzi RE, Watkins PC, Ottina $K$, Wallace MR, Skaguchi AY, Young AB, Shoulson I, Bonilla E, Martin JB (1983) A polymorphic DNA marker genetically linked to Huntington's disease. Nature 306: 234-238

Received: 9 January 1987;

and in revised form: 1 June 1987

Dr. S.C. Elbein

Division of Endocrinology and Metabolism

Rm. 4C216

University of Utah School of Medicine

Salt Lake City, UT 84132

USA 